\title{
Association of Retinal Vascular Manifestation and Obstructive Sleep Apnea (OSA): A Narrative Review
}

\author{
Ali A Al Saeed (iD) \\ Norah S AlShabib ${ }^{2}$ \\ Abdulaziz A Al Taisan (iD) ${ }^{3}$ \\ Yahya A Kreary ${ }^{4}$ \\ 'College of Medicine, King Faisal \\ University, Al-Ahasa, Saudi Arabia; \\ ${ }^{2}$ College of Medicine, King Saud \\ University, Riyadh, Saudi Arabia; \\ ${ }^{3}$ Department of Ophthalmology, College \\ of Medicine, King Faisal University, Al- \\ Ahasa, Saudi Arabia; ${ }^{4}$ Department of \\ Vitreoretinal Surgery, Dhahran Eye \\ Specialist Hospital, Dhahran, Eastern \\ Province, Saudi Arabia
}

\begin{abstract}
Obstructive sleep apnea (OSA) is characterized by frequent episodes of partial or complete obstruction of the airway during sleep causing repeated episodes of apnea. OSA is more prevalent in middle-aged and older adults. OSA is associated with numerous ocular manifestations, including retinal manifestations. Literature highlighted the clear association between OSA and numerous ocular conditions including glaucoma and papilledema. This comprehensive and narrative review aims to summarize up-to-date clinical research concerning the association of OSA and vascular conditions that affect the retina. OSA is associated with the central serous chorioretinopathy (CSC), retinal vein occlusion (RVO), hypertensive retinopathy (HTRP) and development of diabetic retinopathy (DR). Sympathetic activation, hypoxia, and hormonal dysregulation all lead to serious retinal vascular conditions that will worsen OSA patients' quality of life. It is important to refer patients with newly diagnosed OSA to an ophthalmology clinic for the appropriate test.
\end{abstract}

Keywords: obstructive sleep apnea, central retinal vein occlusion, hypertensive retinopathy, diabetic retinopathy, central serous chorioretinopathy

\section{Introduction}

\section{What's Obstructive Sleep Apnea?}

Obstructive sleep apnea (OSA) is characterized by repeated episodes of partial and complete obstruction of the airway during sleep, resulting in recurrent apnea and hypopnea. ${ }^{1,2}$ As a result of poor quality of sleeping, OSA associated with excessive daytime sleepiness occurred in $6 \%$ of men and $4 \%$ of women with OSA. ${ }^{1}$ According to Franklin KA, Lindberg $\mathrm{E}$ in their epidemiological study of OSA, eleven published studies estimated that the prevalence of obstructive sleep apnea to be $22 \%$ in men (range, $9-37 \%$ ) and $17 \%$ (range, $4-50 \%$ ) in women. ${ }^{1}$

\section{Systemic Response to OSA}

OSA results in hypoxemia and hypercapnia, which in turn lead to enhanced sympathetic vasoconstrictor activity and systemic hypertension. It is associated with a number of cardiovascular complications, such as myocardial ischemia, arrhythmias, and congestive heart failure, ${ }^{3}$ as well as other life-threatening incidents, such as motor vehicle crashes (Figure 1). ${ }^{4}$

\section{Severity of OSA}

OSA severity is estimated with apnea-hypopnea index (AHI). AHI which measures the number of apnea or hypopnea per hour during sleep. OSA is defined when the AHI is $\geq 5$. OSA considered to be severe if AHI $<30$ (Table 1). ${ }^{1}$ 


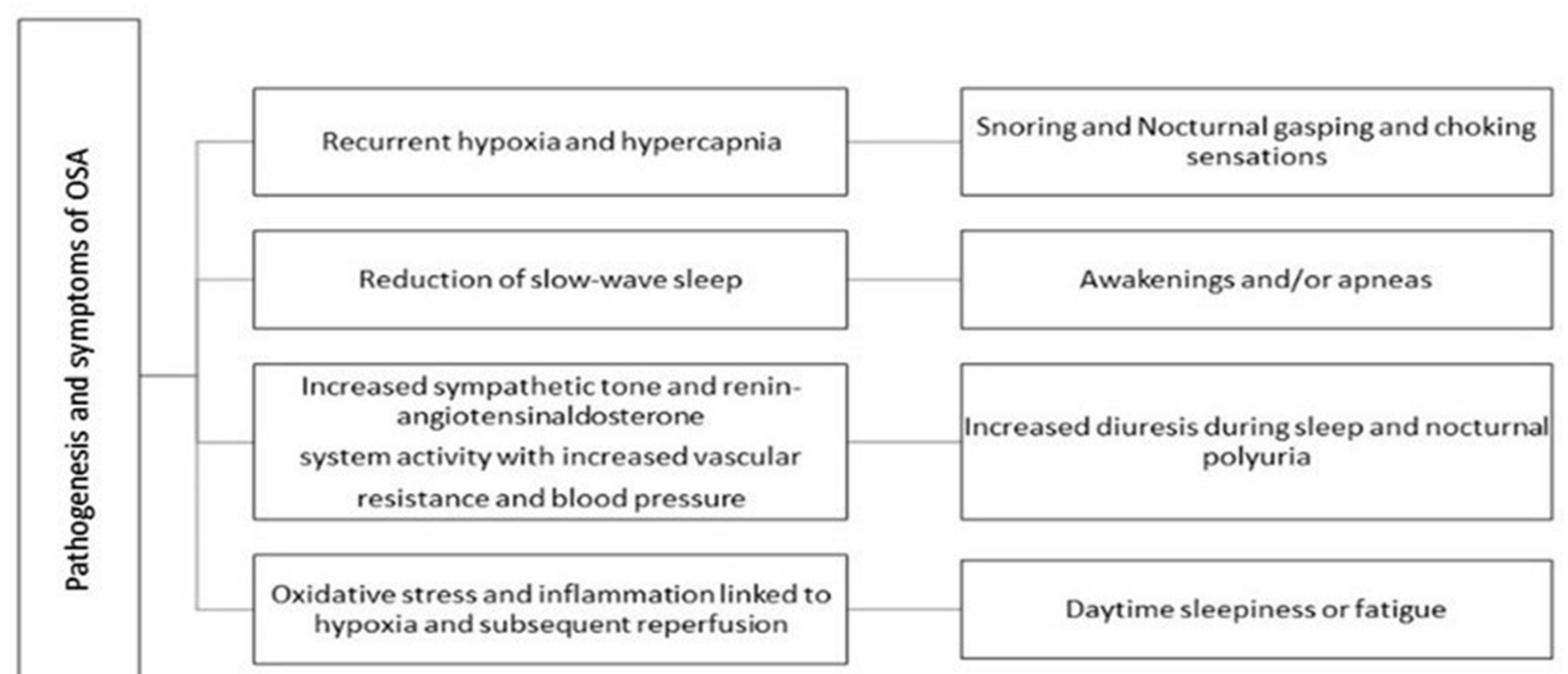

Figure I Symptoms of OSA and underlying mechanism.

\section{Risk Factors of OSA}

The prevalence increases with age, as well as increased body mass index, waist-to-hip ratio, and neck circumference. Moreover, other associations play an important role in the development of sleep apnea, examples of which include abnormalities in mandibular or maxillary size and position, narrow nasal cavities, and enlarged tonsils. Additionally, the increased risk of OSA amongst families with OSA patients suggests a genetic disposition to the disorder. ${ }^{5}$ Moderate to severe forms of OSA (AHI $\geq 15$ ) are prevalent amongst men and women aged between thirty- and 70-year old at percentages of $13 \%$ and $6 \%$, respectively. ${ }^{6}$

\section{OSA and Ocular Disorders}

OSA is associated with numerous ocular disorders, including floppy eyelid syndrome (FES), ${ }^{7}$ non-arteritic anterior ischemic optic neuropathy, ${ }^{7}$ glaucoma,${ }^{8,9}$ papilledema,${ }^{10}$ central serous chorioretinopathy $\mathrm{CSC},{ }^{11}$ and central retinal vein occlusions

Table I Severity of OSA According to AHI (Apnea Hypo Apnea Index)

\begin{tabular}{|l|l|}
\hline AHI & Severity \\
\hline$>5$ & Normal (No Obstructive Sleep Apnea) \\
$5-15$ & Mild Obstructive Sleep Apnea \\
$15-30$ & Moderate Obstructive Sleep Apnea \\
$>30$ & Severe Obstructive Sleep Apnea \\
\hline
\end{tabular}

Abbreviation: $\mathrm{AHI}$, apnea hypo apnea index.
(CRVOs). ${ }^{12}$ Owing to its high oxygen consumption, the retina is one of the most metabolically active tissues in the human body. Therefore, the retina often manifests changes secondary to hypoxic disorders like OSA earlier than other ocular manifestations in the disease course. ${ }^{13}$

Retinal vascular disorders represent a substantial economic burden to healthcare systems. In 2019, Moshfeghi expected diabetic retinopathy alone to cost the US healthcare system $\$ 4.5$ billion in $2020 .^{14}$ It is of paramount importance to recognize that the association between sight-threatening retinal disorders and OSA is beneficial not only for the decrease of economic burdens but also for the preservation of the patients' visual function as this would in turn improve OSA patients' quality of life.

\section{Review Purpose}

This following review is directed at ophthalmologists, and its purpose is to discuss the proposed mechanism involved in the pathogenesis of retinal vascular manifestation associations and OSA. To find the relevant papers, a search was performed on PubMed and Google Scholar. The keywords were as follows: sleep apnea, obstructive sleep apnea, apnea-hypopnea neuropathy, central retinal vein occlusion, diabetic retinopathy, hypertensive retinopathy and central serous chorioretinopathy.

\section{Diabetic Retinopathy and OSA}

Diabetes mellitus is recognized as a serious public health concern with a negative major impact on human life and 
healthcare systems. Globally, 1 in 11 adults has diabetes mellitus (DM) (90\% is having type 2 diabetes mellitus). ${ }^{15}$ Moreover, around one-third of patients with diabetes mellitus are estimated to have diabetic retinopathy, with onethird of those having severe non-proliferative diabetic retinopathy (NPDR). ${ }^{16} \mathrm{~A}$ significant association between diabetic retinopathy and OSA has been noted in the literature.

\section{Two-Way Relationship}

Literature describes the relationship between OSA and DM as two-way, as OSA may increase the risk of developing diabetes and diabetes is a risk factor for developing OSA. A study of 360,250 patients has found that the ratio of the incidence of OSA in patients with type 2 DM compared with the incidence of OSA in nondiabetics is $1.48(\mathrm{P}<0.001) .{ }^{17}$ At the same time, in their metaanalysis of OSA and DR, Zhu et al find that having OSA is significantly associated with an increased risk of DR. ${ }^{18}$

Apnea-Hypopnea Index as an Indicator of DR Progression The severity of OSA is classified according to the ApneaHypopnea Index (AHI) value, with an AHI value of 5-15 considered mild, an AHI value of 15-30 considered moderate and an AHI value $\geq 30$ considered severe Table 1. ${ }^{19}$ Studies demonstrate that the increase in the number of apneic and hypoxic events per sleep hour is positively correlated with the progression of non-proliferative DR into proliferative $\mathrm{DR} .{ }^{20}$ However, the $\mathrm{AHI}$ is not the only indicator of DR progression in OSA; a drop in the mean $\mathrm{SpO} 2$ of below $90 \%$ has also been observed to be positively correlated with development of diabetic macular edema. ${ }^{20}$

\section{Pathogenesis of DR and OSA}

It is hypothesized that dysregulation of circadian locomotor output cycles kaput (CLOCK) genes is directly related to the pathogenesis of $\mathrm{DR}$ in patients with type $2 \mathrm{DM}^{21}$ CLOCK genes play a vital role in the coordination of circadian metabolism and homeostasis. A potential mechanism underlying increased rates of neovascularization in OSA is an increase in the retinal vascular endothelial growth factor expression as a result of hypoxia-induced upregulation of the CLOCK genes. ${ }^{21}$

\section{Continuous Positive Airway Pressure Stops the Progression DR in OSA}

Continuous positive airway pressure (CPAP) is usually indicated in moderate and severe OSA. It has been observed that CPAP improves sleep quality and reduces daytime sleepiness and fatigue along with decreasing mortality and morbidities associated with OSA. ${ }^{19}$ Studies demonstrate that OSA patients treated with CPAP early have a significantly lower prevalence of retinopathy compared to those who were not treated (OR 0.54, $\mathrm{P}=0.04){ }^{22}$ Although early treatment with CPAP improves the anatomical outcomes in patients with OSA, retinal nerve fiber layer thickness, and macular thickness, improvement in visual functions of the eye is not observed. ${ }^{23}$ This indicates that the role of CPAP is to stop the progression of DR in OSA patients, which might help the standard DR treatment achieve the maximum therapeutic goal. ${ }^{23}$

\section{CRVO and OSA}

\section{Literature on CRVO and OSA Association}

Epidemiological studies consider CRVO the second most common cause of blindness from vascular disease in the retina, the first most common cause being DR. ${ }^{24}$ Leroux les Jardins et $\mathrm{al}^{25}$ report three cases of RVO with OSA. Since then, an association between RVO and OSA has been well observed in relevant literature. Notably, by means of screening RVO patients with polysomnography, a prospective and controlled study has concluded that there is a high OSA prevalence among said patients and has sequentially suggested that OSA is a potential risk factor for RVO. ${ }^{26}$ Wan et al found that OSA incidence was remarkably increased in the RVO patients comparing with the control group. ${ }^{27}$ Wang et al found the average $\mathrm{AHI}$ and was significantly higher in CRVO patients (AHI: $13.86 \pm 8.63)^{28}$

\section{Mechanisms of CRVO and OSA Association}

Mechanisms for this correlation derive from the effect of OSA on blood flow autoregulation and microvasculature. Hypertension is associated with OSA and is known as a risk factor for CRVO. ${ }^{4}$ Additionally, the hypercoagulable state following slow retinal blood flow in OSA secondary to hypoxemia and nocturnal intracranial pressure elevations has been suggested to play a key role in increasing the probabilities of CRVO. ${ }^{29}$ Last but not least, increased sympathetic activation, peripheral vasoconstriction, oxidative stress, and endothelial damage as a result of hypoxia episodes in patients with OSA have been postulated as crucial in the development of CRVO. ${ }^{27}$

\section{HTRP and OSA}

Hypertension is a well-known major risk factor for cardiovascular disease and all-cause mortality worldwide, with 
a global burden of 1.38 billion people $(31.1 \%$ of adult population) in $2010 .{ }^{30}$ About $83.6 \%$ of total hypertensive patients were found to have HTRP, as recorded by Kabedi et al (grade 1: 42.1\%; grade 2: $11.3 \%$; grade 3: $23.3 \%$; grade $4: 6.9 \%) .{ }^{31}$ A study by Viren et al estimates that 30 $40 \%$ of hypertensive patients have OSA and $50 \%$ of OSA patients are hypertensive. ${ }^{32}$

\section{$\mathrm{AHI}$ as a Predictor of Retinal Arteriolar Changes}

In a prospective study of the ocular fundus, patients with severe OSA (as defined by AHI $\geq 20$ and hypoxic burden $\geq 10 \%$ ) were three times more likely to have retinal vascular changes in line with mild HTRP, such as arteriolar narrowing, arteriolar sclerosis, and arteriovenous nicking. However, after adjusting for hypertension as a confounder, arteriolar changes remained more common amongst patients with higher AHI $(p=0.04)$. In conclusion, AHI $>40$ doubles the risk of retinal vascular changes independent of blood pressure measurement. ${ }^{33}$ Furthermore, Jessica $\mathrm{Y}$. et al concluded that there is a significant inverse association between AHI and static markers of retinal arteriolar narrowing, such as arterio-venous ratio $(p=0.008)$ and central retinal arteriolar equivalent $(p=0.016)$, irrespective of mean arterial pressure. ${ }^{34}$ Such findings may not have been in line with the hypothesis that $\mathrm{AHI}$ as a predictor of retinal arteriolar changes. However, despite this limitation, we believe that further studies exploring the association between the two are of paramount importance.

Proposed Mechanism of Hypertensive Retinopathy in OSA OSA leads to an increase in systemic blood pressure through various mechanisms. A potential but not exhaustive list of examples includes activation of the reninangiotensin-aldosterone system, decreased stimulation of pulmonary stretch receptors, increased levels of endothelin-1, and bouts of sympathetic activity caused by nocturnal hypoxia and exacerbated by rapid eye movement. ${ }^{35}$ Various studies of subjects at high altitude have described different ocular changes on fundus photography, such as retinal hemorrhages, cotton wool spots, and optic disc edema. Therefore, it is hypothesized that hypoxia blunts autoregulation and promotes compensatory mechanisms in retinal vasculature. ${ }^{36}$

\section{CSC and OSA}

CSC is an ocular disease characterized by decompensation of the retinal pigment epithelium and hyperpermeability of the choroidal vasculature, resulting in neuroretinal detachment. An incidence of 10 per 100,000 men and 2 per 100,000 women is reported by Xie et al, 2008. ${ }^{36}$ Patients affected by CSC are typically presented with central scotoma, micropsia, metamorphopsia, or loss of central vision. ${ }^{37}$

\section{Literature on CSC and OSA Association}

A retrospective case-controlled study conducted by Leveque et al concludes that the risk of OSA is significantly greater in CSC patients than in control subjects (odds ratio $=3.67 ; 95 \% \mathrm{CI}: 1.02,13.14 ; \mathrm{P}=0.046$ ). In the study, $17(58.6 \%)$ out of 29 CSC patients had an increased risk for OSA compared to nine $(31.0 \%)$ of the 29 control subjects. However, potential limitations involve the implementation of the Berlin questionnaire, a selfreport tool with a positive predictive value of $89 \%$, a sensitivity of 86 and a specificity of $77 \%$, as opposed to the golden standard of PSG. ${ }^{37}$

Similarly, Kloos et al screened CSC patients for the risk of OSA with the Epworth Sleep Scale (sensitivity = $66 \%$ and specificity $=48 \%$ at an Epworth sleep scale score $>10$ ), followed by PSG. Kloos et al report that $22 \%$ of CSC patients were found to have OSA, which, they cite, is higher than the general population. ${ }^{11}$ Conversely, a higher prevalence of OSA based on more recent epidemiologic data may not have been taken into account.

In contrast, Frank et al did not detect a statistically significant association between CSC and OSA in their study, which controlled for BMI and used a larger cohort of patients. This indicates that previous results reported by Brodie et al may have been attributed to the confounder of BMI. ${ }^{38}$ However, an association between CSC and OSA has been established in more recent studies. For example, a nationwide population-based study with the Taiwan National Health Insurance Database has identified 10,753 OSA patients and 322,590 control subjects and confirmed that, between the two, the incidence of CSC was significantly higher in OSA (adjusted incident rate ratio for probable SA: 1.2 [95\% CI: 1.1-1.4], $\mathrm{P}<0.0001) .{ }^{39}$ Similarly, Pan et al queried over 59 million OSA patients and identified those with a more restrictive definition of OSA (patients who had undergone a sleep study and had a record of receiving a CPAP device) and concluded that the risk of CSC is significantly increased with OSA diagnosis $(\mathrm{HR}=1.081, P<0.033) .{ }^{40}$

\section{Proposed Mechanism of CSC in OSA}

Increased levels of epinephrine, norepinephrine and corticosteroids are hypothesized to be the main pathophysiology 
underlying the association between CSC and OSA. Increased catecholamines are thought to be due to intermittent asphyxia and sudden arousal from sleep. Similarly, pulsatile corticosteroids release occurs during nocturnal arousals, and corticosteroid levels are believed to be increased in sleepdeprived patients. Furthermore, norepinephrine stimulates corticotrophin and leads to the additive effect of further cortisol release. ${ }^{37}$

\section{CPAP and CSC}

A case report on bilateral CSC that resolved rapidly after starting CPAP machine therapy further supports the proposed association between CSC and OSA. ${ }^{41}$ Furthermore, Liu et al have concluded that suspected OSA patients who received CPAP had a significantly decreased CSC incidence rate, as opposed to the non-CPAP group. ${ }^{39}$

\section{Conclusion}

OSA is common, and its prevalence is climbing with the increased prevalence of obesity, alongside other risk factors. OSA is still underdiagnosed and only $15 \%$ of those who are symptomatic receive OSA treatment. There is a growing body of literature showing a relationship between OSA and various sight-threatening ocular conditions, including retinal vascular manifestation. Sympathetic activation, hypoxia, and hormonal dysregulation all lead to a number of retinal vascular conditions that will worsen OSA patients' quality of life. Early detection with appropriate intervention of any retinal vascular condition can decrease the burden of OSA. This necessitates an early referral to undergo sleep studies for those with poorly controlled hypertensive retinopathy and nonarteritic anterior ischemic optic neuropathy.

\section{Abbreviation}

OSA, obstructive sleep apnea; CRVO, central retinal vein occlusion; HTR, hypertensive retinopathy; DR, deiabetic retinopathy; CSC, central serous chorioretinopathy; AHI, apnea hypo apnea index; DM, diabetes mellitus; CPAP, continuous positive airway pressure.

\section{Funding}

Self-funded.

\section{Disclosure}

The authors report no conflicts of interest for this work.

\section{References}

1. Franklin KA, Lindberg E. Obstructive sleep apnea is a common disorder in the population-a review on the epidemiology of sleep apnea. J Thorac Dis. 2015;7(8):1311-1322. doi:10.3978/j.issn.20721439.2015.06.11

2. Dempsey JA, Veasey SC, Morgan BJ, O’Donnell CP. Pathophysiology of sleep apnea [published correction appears in Physiol Rev.2010 Apr; 90(2):797-8]. Physiol Rev. 2010;90 (1):47-112. doi:10.1152/physrev.00043.2008

3. Dorasamy P. Obstructive sleep apnea and cardiovascular risk. Ther Clin Risk Manag. 2007;3(6):1105-1111.

4. Tregear S, Reston J, Schoelles K, Phillips B, Obstructive sleep apnea and risk of motor vehicle crash: systematic review and meta-analysis. J Clin Sleep Med. 2009;5(6):573-581. doi:10.5664/jcsm.27662

5. Young T, Skatrud J, Peppard PE. Risk factors for obstructive sleep apnea in adults. JAMA. 2004;291(16):2013-2016. doi:10.1001/ jama.291.16

6. Rana D, Torrilus C, Ahmad W, et al. Obstructive sleep apnea and cardiovascular morbidities: a review article. Cureus. 2020;12(9): e10424. doi:10.7759/cureus.10424

7. Palombi K, Renard E, Levy P, et al., Non-arteritic anterior ischaemic optic neuropathy is nearly systematically associated with obstructive sleep apnoea. Br J Ophthalmol. 2006;90(7):879-882. doi:10.1136/ bjo.2005.087452

8. Mojon DS, Hess CW, Goldblum D, et al. High prevalence of glaucoma in patients with sleep apnea syndrome. Ophthalmology. 1999;106(5):1009-1012. doi:10.1016/S0161-6420(99)00525-4

9. Sergi M, Salerno DE, Rizzi M, et al. Prevalence of normal tension glaucoma in obstructive sleep apnea syndrome patients. J Glaucoma. 2007;16(1):42-46. doi:10.1097/01.ijg.0000243472.51461.24

10. Purvin VA, Kawasaki A, Yee RD. Papilledema and obstructive sleep apnea syndrome. Arch Ophthalmol. 2000;118(12):1626-1630. doi:10.1001/archopht.118.12.1626

11. Kloos P, Laube I, Thoelen A. Obstructive sleep apnea in patients with central serous chorioretinopathy. Graefes Arch Clin Exp Ophthalmol. 2008;246(9):1225-1228. doi:10.1007/s00417-008-0837-0

12. Shah SM, Bakri SJ. Obstructive sleep apnea evaluation in retinal vein occlusion patients: an opportunity for multidisciplinary care? Can J Ophthalmol. 2020;55(4):284-285. doi:10.1016/j.jcjo.2020.03.004

13. Wang XY, Wang S, Liu X, et al. Retinal vascular morphological changes in patients with extremely severe obstructive sleep apnea syndrome. Chin Med J (Engl). 2017;130(7):805-810. doi:10.4103/0366-6999.202728

14. Moshfeghi A. Evaluating the social costs of blindness from AMD. Presentation at: Retina World Congress; March 2019; Fort Lauderdale, FL. Available from: https://www.healio.com/news/ ophthalmology/20190323/social-cost-of-retinal-blindness-in-us-willbe-billions-of-dollars-by-2020. Accessed July 29, 2021.

15. Sapra A, Bhandari P. Diabetes mellitus. StatPearls [Internet]. Treasure Island (FL): StatPearls Publishing; Jan, 2020 [updated November 19, 2020]. Available from: https:/www.ncbi.nlm.nih.gov/ books/NBK551501/. Accessed July 29, 2021.

16. Lee R, Wong TY, Sabanayagam C, Epidemiology of diabetic retinopathy, diabetic macular edema and related vision loss. Eye Vision. 2015;2(1):17. doi:10.1186/s40662-015-0026-2

17. Subramanian A, Adderley NJ, Tracy A, et al. Risk of incident obstructive sleep apnea among patients with type 2 diabetes. Diabetes Care. 2019;42(5):954-963.

18. Zhu Z, Zhang F, Liu Y, et al. Relationship of obstructive sleep apnoea with diabetic retinopathy: a meta-analysis. Biomed Res Int. 2017;2017:4737064. doi:10.1155/2017/4737064

19. Epstein LJ, Kristo D, Strollo PJ Jr, et al. Adult obstructive sleep apnea task force of the American academy of sleep medicine. Clinical guideline for the evaluation, management and long-term care of obstructive sleep apnea in adults. $J$ Clin Sleep Med. 2009;5:263-276. 
20. Shiba T, Sato Y, Takahashi M. Relationship between diabetic retinopathy and sleep-disordered breathing. Am J Ophthalmol. 2009;147 (6):1017-1021. doi:10.1016/j.ajo.2008.12.027

21. Kusunose N, Akamine T, Kobayashi Y, et al. Contribution of the clock gene DEC2 to VEGF mRNA upregulation by modulation of HIF1a protein levels in hypoxic MIO-M1 cells, a human cell line of retinal glial (Müller) cells. Jpn J Ophthalmol. 2018;62 (6):677-685.

22. Nishimura A, Kasai T, Kikuno S, et al. Apnea hypopnea index during rapid eye movement sleep with diabetic retinopathy in patients with type 2 diabetes. J Clin Endocrinol Metab. 2019;104(6):2075-2082.

23. Lin PW, Lin HC, Friedman M, et al. Effects of CPAP for patients with OSA on visual sensitivity and retinal thickness. Sleep Med. 2020;67:156-163. doi:10.1016/j.sleep.2019.10.019

24. Huon LK, Liu SY, Camacho M, Guilleminault C, The association between ophthalmologic diseases and obstructive sleep apnea: a systematic review and meta-analysis. Sleep Breath. 2016;20 (4):1145-1154. doi:10.1007/s11325-016-1358-4

25. Leroux Les Jardins G, Glacet-Bernard A, Lasry S, Housset B, Coscas G, Soubrane G, Retinal vein occlusion and obstructive sleep apnea syndrome. J Fr Ophtalmol. 2009;32(6):420-424. doi:10.1016/ j.jfo.2009.04.012

26. Felfeli T, Alon R, Adel FA. Screening for obstructive sleep apnea amongst patients with retinal vein occlusion. Can J Ophthalmol. 2020;10:1016.

27. Wan W, Wu Z, Lu J, et al. Obstructive sleep apnea is related with the risk of retinal vein occlusion. Nat Sci Sleep. 2021;13:273-281. doi:10.2147/NSS.S290583

28. Wang YH, Zhang P, Chen L, et al. Correlation between obstructive sleep apnea and central retinal vein occlusion. Int $J$ Ophthalmol. 2019;12(10):1634-1636. doi:10.18240/ijo.2019.10.17

29. Grover DP, Obstructive sleep apnea and ocular disorders. Curr Opin Ophthalmol. 2010;21(6):454-458. doi:10.1097/ICU.0b013e32833f0 Odc

30. mills KT, Stefanescu A, He J. The global epidemiology of hypertension. Nat Rev Nephrol. 2020;16(4):223-237. doi:10.1038/ s41581-019-0244-2

31. Kabedi NN, Mwanza JC, Lepira FB, Kayembe TK, Kayembe DL. Hypertensive retinopathy and its association with cardiovascular, renal and cerebrovascular morbidity in Congolese patients. Cardiovasc J Afr. 2014;25(5):228-232. doi:10.5830/CVJA-2014045
32. Viren SK, White DP, Amin R, et al. Sleep apnea and cardiovascular disease: an American Heart Association/American College of Cardiology foundation scientific statement from the American heart association council for high blood pressure research professional education committee, council on clinical cardiology, stroke council, and council on cardiovascular nursing. J Am Coll Cardiol. 2008;52 (8):686-717. doi:10.1016/j.jacc.2008.05.002

33. Fraser CL, Bliwise DL, Newman NJ, et al. A prospective photographic study of the ocular fundus in obstructive sleep apnea. $J$ Neuroophthalmol. 2013;33(3):241-246. doi:10.1097/WNO.0b013e $318290194 \mathrm{f}$

34. Tong JY, Golzan M, Georgevsky D, et al. Quantitative retinal vascular changes in obstructive sleep apnea. Am $J$ Ophthalmol. 2017;182:72-80. ISSN 0002-9394. doi:10.1016/j. ajo.2017.07.012

35. Kario K. Obstructive sleep apnea syndrome and hypertension: mechanism of the linkage and 24-h blood pressure control. Hypertens Res. 2009;32(7):537-541. doi:10.1038/hr.2009.73

36. Xie Y, Wang N. The eye and high altitude. In: Wang N, editor. Integrative Ophthalmology. Advances in Visual Science and Eye Diseases. Vol. 3. Singapore: Springer; 2020. doi:10.1007/978-98113-7896-6_15

37. Kitzmann AS, Pulido JS, Diehl NN, Hodge DO, Burke JP. The incidence of central serous chorioretinopathy in Olmsted County, Minnesota, 1980-2002. Ophthalmology. 2008;115(1):169-173. doi:10.1016/j.ophtha.2007.02.032

38. Brodie FL, Charlson ES, Aleman TS, et al. Obstructive sleep apnea and central serous chorioretinopathy. Retina. 2015;35(2):238-243. doi:10.1097/IAE.0000000000000326

39. Liu PK, Chang YC, Tai MH, et al. The association between central serous chorioretinopathy and sleep apnea: a Nationwide Population-Based Study. Retina. 2020;40(10):2034-2044. doi:10. 1097/iae.0000000000002702

40. Pan CK, Vail D, Bhattacharya J, Cao M, Mruthyunjaya P. The effect of obstructive sleep apnea on absolute risk of central serous chorioretinopathy. Am J Ophthalmol. 2020;218:148-155. doi:10. 1016/j.ajo.2020.05.040

41. Jain AK, Kaines A, Schwartz S. Bilateral central serous chorioretinopathy resolving rapidly with treatment for obstructive sleep apnea. Graefes Arch Clin Exp Ophthalmol. 2010;248(7):1037-1039. doi:10.1007/s00417-009-1257-5
Clinical Ophthalmology

\section{Publish your work in this journal}

Clinical Ophthalmology is an international, peer-reviewed journal covering all subspecialties within ophthalmology. Key topics include: Optometry; Visual science; Pharmacology and drug therapy in eye diseases; Basic Sciences; Primary and Secondary eye care; Patient Safety and Quality of Care Improvements. This journal is indexed on PubMed

\section{Dovepress}

Central and CAS, and is the official journal of The Society of Clinical Ophthalmology (SCO). The manuscript management system is completely online and includes a very quick and fair peer-review system, which is all easy to use. Visit http://www.dovepress.com/ testimonials.php to read real quotes from published authors. 